\title{
Museu Antropológico do Vale do São Francisco
}

\section{Zanoni Neves}

Coordenador do Museu Antropológico do Vale do São Francisco em Belo Horizonte. Mestre em Antropologia Social pela Unicamp. Belo Horizonte [MG] Brasil. <zanonineves@ig.com.br>

\section{Resumo}

O Museu Antropológico do Vale do São Francisco - MAVSF — foi criado com três objetivos fundamentais: o ensino, a pesquisa e a difusão de manifestações culturais da ribeira. Possui doze mostruários em que está representado o rico artesanato regional sem contar os objetos históricos que contribuem para uma visão mais abrangente da cultura material dos ribeirinhos, sobretudo, de seus povos tradicionais. Fotografias e documentos históricos, sem se perder de vista as fotografias atuais resultantes de viagens de pesquisa, auxiliam o visitante na percepção e compreensão do patrimônio material da ribeira, oferecendo também algum conhecimento sobre o seu patrimônio imaterial. Enfim, o MAVSF foi organizado para que a sociedade brasileira conheça uma das regiões mais importantes do ponto de vista histórico-geográfico e cultural do país.

\section{Palavras-chave}

Museu Antropológico. Rio São Francisco. Patrimônio. História. Ensino. Pesquisa.

\section{The Anthropological Museum from Sao Francisco Valley [Brazil]}

\begin{abstract}
This article intend to demonstrate the importance of the "Museu Antropológico do Vale do São Francisco"MAVSF - for the education, the research and the diffusion of São Francisco riparians heritage. Thus, we desire to emphasize that the museal knowledge is valuable for the sciences advance: students, teachers and researchers, everybody, may to learn at the MAVSF.
\end{abstract}

\section{Keywords}

Anthropological Museum. São Francisco River. Heritage. History. Education. Research. 


\section{Introdução}

Recentemente inaugurado, o Museu Antropológico do Vale do São Francisco (MAVSF) localiza-se em Belo Horizonte a trinta minutos do Rio das Velhas e um pouco mais distante do Paraopeba dois importantes afluentes do grande rio. Assim, não se pode esquecer que a Capital mineira pertence à bacia do Velho Chico.

Trata-se de uma instituição que pode ser classificada como museu de reduções. Em seu acervo, predominam objetos artesanais em tamanho reduzido, representativos de outros bens de caráter utilitário, decorativo e ritual, presentes no dia a dia dos povos da ribeira. Em menor número há um conjunto de objetos históricos que contribui para melhor compreendermos a cultura material dos ribeirinhos.

Em outra oportunidade, foi elaborado o conceito de cultura material como [...]

[...] a dimensão da cultura que abrange a elaboração e o uso de bens materiais concebidos pelo homem na produção e reprodução de sua existência, sem se perder de vista o aspecto simbólico dos bens nas diversas sociedades e grupos sociais. Alguns bens materiais são diretamente utilizados para transformar a natureza; outros cumprem funções rituais $e$ decorativas. Vale ressaltar, ainda, que alguns assumem função relevante como componentes da identidade de grupos sociais, etnias e sociedades. Nas reflexões sobre cultura material, não se pode perder de vista a dimensão imaterial do saber, que é transmitida de geração a geração e, sincronicamente, entre indivíduos e entre grupos sociais, o que possibilita a elaboração e reelaboração dos bens, sua utilização e transformação (Neves, 2009, p.23).

As diversas peças que compõem o acervo foram localizadas da seguinte forma conforme o projeto museográfico: em um mostruário de caráter geral, representativo dos afluentes e subregiões, apresentando objetos artesanais confeccionados em materiais diversos; e em onze mostruários temáticos, nos quais são apresentados itens específicos da cultura material ribeirinha. É importante esclarecer que os mostruários temáticos destinam-se a reunir, em unidades específicas, os objetos de mesma natureza, que integram um acervo museal.

No Museu Antropológico do Vale do São Francisco, esses objetos representam itens fundamentais da cultura material da região, e foram agrupados em mostruários específicos, por exemplo, "pesca artesanal", "peixes" etc.

Entre outras funções a desempenhar na sociedade brasileira, o Museu Antropológico do Vale do São Francisco propõe-se a dar uma pequena contribuição para reafirmar a identidade dos povos tradicionais da ribeira, revelando informações acerca de seu trabalho, criatividade, sociabilidade, história e religiosidade. Artesãos, pescadores, roceiros, devotos, estão representados no Museu, seja através da exposição de sua cultura material, seja através do registro de seu patrimônio imaterial. Nesse particular, um acervo de documentos e fotografias históricas e atuais que está arquivado na reserva técnica da instituição, ficará exposto para os visitantes e será ampliado em futuras viagens de pesquisa.

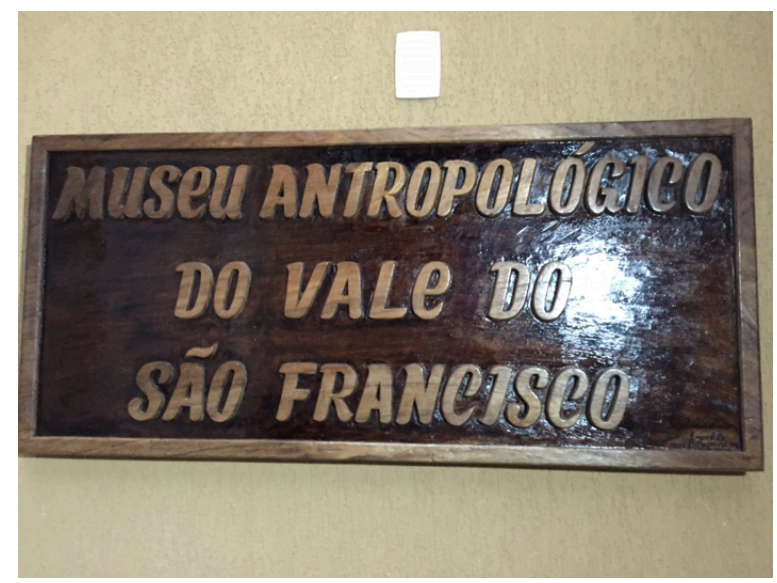

Assim, pode-se afirmar que esta instituição deseja contribuir para a visibilidade de manifestações culturais dos povos ribeirinhos sem perder de vista a preservação de sua memória social.

Figura 1. Placa do Museu Antropológico do Vale do São Francisco confeccionada pelo artesão Expedito Viana Rodrigues, de Pirapora [MG]. Foto: Carlos Isoldi, 2017. 
O conteúdo deste artigo já foi objeto de palestras ministradas pela equipe do Museu Antropológico do Vale do São Francisco em duas oportunidades: em 20 de maio de 2017, no auditório do Instituto Histórico e Geográfico de Minas Gerais em Belo Horizonte; e, em 22 de junho de 2017, na sala de aulas deste Museu. Em 2016 foi publicada uma versão resumida deste artigo, apresentando informações sobre o projeto museográfico da instituição com destaque para o conteúdo dos mostruários temáticos (Neves, 2016, p.143).

\subsection{0 espaço físico}

O espaço físico do Museu Antropológico do Vale do São Francisco é composto pelos seguintes ambientes:

- Área ocupada pelo Museu: $210 \mathrm{~m}^{2}$

- Área de exposição permanente: $69 \mathrm{~m}^{2}$

- Sala de palestras, cursos e exposições temporárias: $30 \mathrm{~m}^{2}$

- Mobiliário: 25 carteiras escolares, Smart TV

- Jardins: $40 \mathrm{~m}^{2}$ (onde serão expostas algumas esculturas); ao todo, três jardins.

- Biblioteca e Secretaria: $11 \mathrm{~m}^{2}$

- Banheiros: $5 \mathrm{~m}^{2}$ (total), sendo dois banheiros (um, adaptado para pessoas com necessidades especiais)

- Copa: 3,20 $\mathrm{m}^{2}$ - espaço contendo pia e armários

- Plataforma para cadeirante.

- Outros espaços: rampa da garagem, escadas etc.

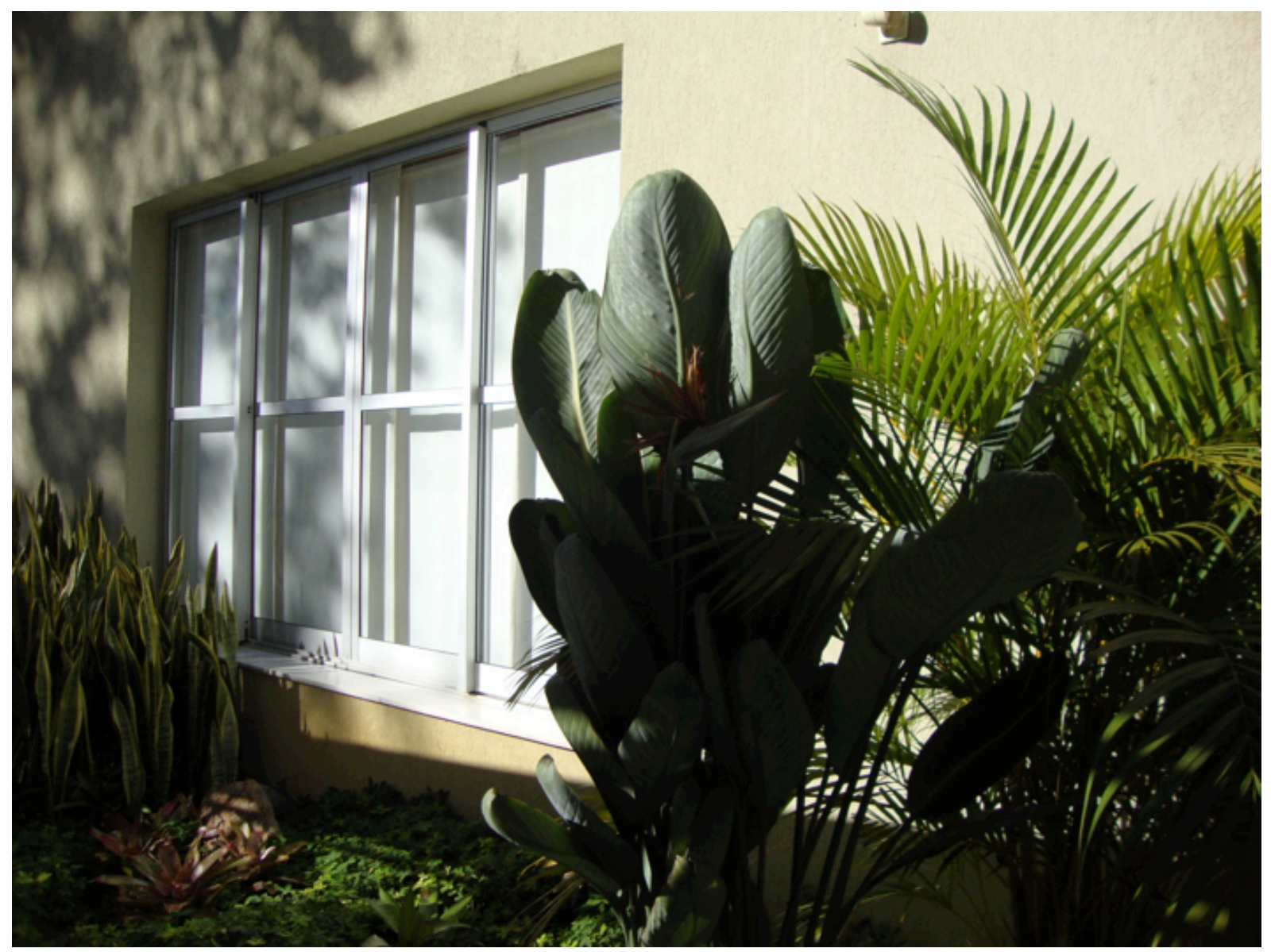

Figura 2. Jardim do Museu Antropológico do Vale do São Francisco. Foto: Tânia Cotta, 2017. 


\section{Alguns itens do Projeto Museográfico}

Ao longo de mais quarenta anos, constituiu-se o acervo do Museu, que se caracteriza pela variedade, no qual se destacam os objetos artesanais provenientes de sub-regiões do São Francisco. Até 1996, era apenas uma coleção de peças resultante de viagens de pesquisa.

Na XX Reunião Brasileira de Antropologia, realizada em Salvador-BA no período de 14 a 18 de abril de 1996, a coleção foi objeto de uma comunicação e discussão no GT 22, no qual se consolidou a ideia de fundação do Museu.

No mostruário central do Museu, intitulado "Navegação \& Carrancas", há réplicas, em tamanho reduzido, de diversas embarcações que singraram (singram) as águas do grande rio e de seus afluentes: canoas, vapores, barcas de figura, canoas de tolda, barcas motorizadas, etc. No mesmo mostruário podem ser observados vários exemplares das famosas carrancas confeccionadas por artesãos de Pirapora [MG], Juazeiro [BA], Petrolina [PE], Santa Maria da Vitória [BA]. Nos dias atuais, as carrancas podem também ser encontradas em residências, escritórios e museus e em poder de colecionadores.

Há outros mostruários, também considerados temáticos, apresentando informações específicas sobre a cultura material ribeirinha. Da PESCA, por exemplo, pode-se conhecer alguns instrumentos como a tarrafa e a grozeira, sem se perder de vista as agulhas utilizadas para confecção de redes, manjubeiras e tarrafas. Uma pequena canoa completa a mostra dos apetrechos de pesca. Já o mostruário da fauna ictiológica (PEIXES) contém peças artesanais representando o dourado, o surubim, o pacamão ("pocomã" conforme a linguagem regional) e a piranha. Confeccionado em madeira, destaca-se um dourado, símbolo de Pirapora [MG]. A LITERATURA DE CORDEL sobre o Rio São Francisco está representada pela exposição de diversos livretos: "A fera de Petrolina", "Peleja de dois poetas sobre a transposição do Rio São Francisco", "A enchente do São Francisco", "As lendas do Rio São Francisco", "500 anos do Rio São Francisco", "A história do São Francisco e o fenômeno das carrancas" etc. Há também outro mostruário, cujo objetivo é apresentar ao visitante A CASA E SEUS UTENSÍLIOS: tacho, gamela, moringa, pilão, regador, cuscuzeiro etc. Esculpido em Juazeiro [BA], um "pilãozeiro", confeccionado em madeira, demonstra-nos como é o trabalho de pilar os cereais no meio rural. Armas do tipo utilizado por jagunços, estribo, carro de bois e objetos históricos diversos compõem um mostruário que remete o visitante ao tempo da dominação coronelística, que predominou durante muitas décadas na região. Esses objetos estão reunidos sob a denominação "NO TEMPO DOS CORONÉIS..." Outro mostruário apresenta ao visitante OBJETOS DE USO PESSOAL utilizados ou confeccionados na região: caneta e chaveiro em forma de carranca, cinto, punhal, anel em metal polido, cachimbo de roceiro etc. A expografia inclui, em outro mostruário específico, 0 TEAR do Vale do Urucuia - representado por novelos e um belo tapete - e O CROCHÊ em forma de "rede de dormir" e tapete, confeccionados em Pirapora [MG]. Há também um mostruário dedicado à COMPANHIA DE NAVEGAÇÃO DO SÃO FRANCISCO, empresa estatal extinta, onde o visitante terá a oportunidade de observar dois pares de insígnias de oficial de bordo dos vapores, bem como um mapa histórico do curso médio do rio entre Pirapora [MG] e Juazeiro [BA] - antes da construção da barragem de Sobradinho. Uma Carteira de Identidade expedida pela referida Companhia, bem como dois timões ("rodas de leme") em tamanho reduzido completam o acervo do referido mostruário. No mostruário denominado COPA \& COZINHA podem ser observados objetos artesanais e históricos recolhidos na região: gamela, pilão, paliteiro, farinheira, confeccionados em madeira; cestos de Barra [BA] e Januária [MG]; lamparina, "ferro de engomar", cuscuzeiro, pratos e uma travessa utilizados na extinta Companhia de Navegação do São Francisco. Uma mostra de LIVROS RAROS, publicados há muitas décadas, porém não reeditados, completa a relação de mostruários temáticos que abrigam o acervo do Museu. 0 livros raros estão sendo restaurados, conservando-se suas capas originais.

Por fim, dezenas de peças em madeira, argila, pedra e metal localizam-se num amplo mostruário, representativo das SUB-REGIÕES E AFLUENTES do São Francisco. Estão ali reunidos objetos dos Rios Corrente, Grande, Verde Grande, Velhas e Jequitaí (afluentes do São Francisco) sem esquecermos os Municípios de Pirapora e Januária [MG], Juazeiro, Barra, Bom Jesus da Lapa [BA], Petrolina [PE], Propriá, Santana de São Francisco [SE], cidades ribeirinhas que são pólos importantes da região. Está representado também o artesanato de uma comunidade quilombola - 
Buriti do Meio - localizada no Município de São Francisco [MG]. O mostruário das SUB-REGIÕES E AFLUENTES cumpre a função de demonstrar ao visitante a diversidade cultural que caracteriza a região sem se perder de vista a criatividade dos povos da ribeira. Transcrevemos abaixo, em resumo, o conteúdo dos diversos mostruários que compõem o Museu Antropológico do Vale do São Francisco:

Tabela 1. Mostruários do Museu Antropológico do Vale do São Francisco.

\begin{tabular}{|c|c|c|c|}
\hline Nomes & Conteúdo & Tipo & $\begin{array}{c}\text { Número de } \\
\text { Peças }\end{array}$ \\
\hline Afluentes e Sub-regiões & Artesanato & De caráter geral & 58 \\
\hline Copa \& Cozinha & Objetos históricos & Temático & 12 \\
\hline Franave & Objetos históricos & Temático & 09 \\
\hline Literatura de Cordel & Folhetos & Temático & 07 \\
\hline Peixes & Artesanato & Temático & 08 \\
\hline Pesca Artesanal & Artesanato & Temático & 07 \\
\hline Tear \& Crochê & Artesanato & Temático & 06 \\
\hline O Tempo dos Coronéis & Objetos históricos & Temático & 06 \\
\hline Casa e seus Utensílios & Artesanato & Temático & 07 \\
\hline Objetos de Uso Pessoal & Artesanato & Temático & 06 \\
\hline Navegação \& Carrancas & Artesanato & Geral & 50 \\
\hline Livros Raros & Livros antigos & Temático & 11 \\
\hline
\end{tabular}

Na reserva técnica do Museu Antropológico do Vale do São Francisco encontram-se centenas de fotografias históricas e atuais. Algumas foram selecionadas para figurarem em quadros na sala de aulas e em outros espaços do recinto. Documentos históricos também estão abrigados nos arquivos do Museu.

Em suas dependências, também funciona o Núcleo de Estudos do Vale do São Francisco que reúne a mais completa biblioteca particular sobre a região sem se perder de vista obras de Antropologia, Museologia, História, Sociologia, Ciência Política, Folclore e literatura em geral. Trata-se de um setor orientado para o ensino e a pesquisa.

O projeto museográfico foi elaborado à luz de duas disciplinas acadêmicas que se complementam - a Museologia e a Antropologia Histórica —, valorizando-se a cultura popular tradicional dos povos da ribeira, sobretudo, o trabalho de artesãos que manipulam materiais diversos para confeccionar seus objetos. $\mathrm{O}$ acervo fotográfico contribui para o registro do patrimônio material e imaterial dos ribeirinhos. Inclui imagens históricas e atuais da região. Nas viagens de pesquisas, os folguedos regionais, as embarcações do São Francisco, seus monumentos e prédios históricos, são fotografados para integrar a reserva técnica do Museu. As fotografias já estão devidamente separadas em coleções: A) Fotografias históricas: A.1. Tripulantes; A.2. Cidades; A.3. Embarcações; A.4. Passageiros; B) Fotografias atuais: B.1. Embarcações; B.2. Cidades; B.3. Monumentos; B.4. Ribeirinhos; B.5. Prédios históricos.

Deve-se ressaltar que o aspecto didático da expografia foi concebido para que a cultura e a história regional sejam facilmente compreendidas e assimiladas pelos visitantes, sobretudo, os estudantes. 
É importante ressaltar mais uma vez que, no Museu Antropológico do Vale do São Francisco, predominam objetos em tamanho reduzido, porém, representativos da cultura material dos povos da ribeira.

Um pequeno acervo de objetos históricos recolhidos na região e utilizados no cotidiano dos ribeirinhos contribui para ampliar o conhecimento sobre a cultura material dos ribeirinhos.

A sala de aulas destina-se a ampliar e consolidar informações sobre as culturas ribeirinhas, a história e a geografia regional. Já está equipada com vinte e cinco carteiras e Smart TV que se destinam, sobretudo, a estudantes e professores. Mas todos os visitantes provenientes da Bacia do Rio São Francisco serão muito bem-vindos ao recinto do Museu. A sala de aula abrigará também exposições temporárias: pintura, esculturas, fotografias etc.

O Museu Antropológico do Vale do São Francisco encontra-se em expansão. Em seu espaço físico, incluindo os jardins, ainda é possível abrigar um significativo número de peças artesanais. Anualmente, sua equipe promove viagens de pesquisa para aquisição de objetos representativos da cultura dos povos ribeirinhos sem perderem de vista o trabalho de fotografar e entrevistar moradores da ribeira.

A inserção de textos concisos nos mostruários visa possibilitar ao estudante, ao estudioso e ao pesquisador acesso a informações de caráter interpretativo, resultantes de pesquisas, sobre a história e as culturas dos povos da ribeira. Cabe repetir: são textos breves, de fácil leitura.

Ao longo da história regional, sucederam-se diversos tipos de embarcações, sobretudo, no Médio e Baixo São Francisco. De diferentes medidas, as embarcações possibilitaram (possibilitam) a comunicação entre os ribeirinhos. Assim, para esclarecimento do visitante, sobretudo, do estudioso, consta um pequeno texto no mostruário dedicado à NAVEGAÇÃO, sem evidentemente comprometer a visão dos objetos: "A diversidade de tipos de embarcações contribui para compreendermos a vocação hidroviária do Rio São Francisco".

A integração econômica das populações ribeirinhas pertencentes a três estados (anteriormente, províncias) da Federação foi possível graças às boas condições de navegabilidade do Médio São Francisco e aos tripulantes das embarcações que singraram suas águas. Nesse sentido, foi introduzido o seguinte texto no mostruário dedicado à navegação: "Barcas, ajoujos e vapores contribuíram para o desenvolvimento do sistema econômico regional, unindo as comunidades ribeirinhas de Minas, da Bahia e de Pernambuco." Também no Baixo São Francisco houve a formação de um sistema econômico regional.

A origem das carrancas, peças fundamentais da identidade regional, é revelada ao visitante no mostruário dedicado à navegação:

"Das antigas figuras de proa originaram-se as atuais carrancas, que servem como objetos de decoração em residências e escritórios, e estão nas proas de modernas embarcações" (MAVSF, 2017).

Vale acrescentar que, nesse mostruário, estão expostas réplicas das antigas barcas de figura bem como carrancas de diversas cidades da região. Trata-se da coleção mais completa, em tamanho reduzido, existente no Brasil.

Sobre a importância da religiosidade popular representada no Museu por esculturas de Jesus Cristo, de São Francisco de Assis e do Santuário de Bom Jesus da Lapa, consta o seguinte texto:

"O artesanato sacro do Vale do São Francisco expressa a intensa religiosidade dos povos da região" (MAVSF, 2017).

Há que se ressaltar que o Museu Antropológico do Vale do São Francisco é uma instituição científica, não estando vinculada a qualquer seita ou religião. 
Os pequenos textos acima mencionados são posicionados nos mostruários de tal forma que não interfiram na visão dos objetos.

\section{Intercâmbio Regional}

O Museu Antropológico do Vale do São Francisco tem um grande interesse em interagir com instituições regionais. Em que pese sua inauguração em data recente, já recebeu ilustres visitantes. De Pirapora, cidade ribeirinha: a Sra. Ercy Guerra, do Museu Camillo dos Santos; a Sra. Ilzerita Gomes de Assis, Srs. Daniel Rodrigues e Daniel Júnior, família dedicada à música regionalista; Sr. Nelson Trindade Cotta Filho e sua esposa, Professora Leda, diretora de um educandário em Pirapora. Da mesma família, esteve em visita ao Museu a Sra. Regina Cotta Queiroz, da Capitania Fluvial dos Portos do São Francisco/Ministério da Marinha, bem como a pedagoga Edna Cotta e as estudantes Lorena e Vitória Cotta. Como se pode constatar, o Museu recebe famílias em suas dependências. Por seu interesse pela pintura regionalista, a professora Maria das Graças Hatem Abreu, proprietária do ateliê que leva seu nome, também visitou o Museu Antropológico do Vale do São Francisco. Jornalista e historiador dedicado à pesquisa em Pirapora, o Sr. Dimas Fulgêncio também conheceu o seu acervo.

Em trabalho de pesquisa, o artista plástico Anderson Dias, da TV Globo, responsável pela reconstituição de embarcações do Rio São Francisco na novela "Velho Chico", também visitou o Museu. Coordenador da Promotoria Estadual de Defesa do Patrimônio Cultural e Turístico de Minas Gerais, Dr. Marcos Paulo de Souza Miranda também nos deu a honra de sua visita.

A equipe responsável pelo Museu, sempre que convidada, comparece a eventos na região do São Francisco. No período de 09 a 12 de novembro de 2016, o Coordenador do Museu Antropológico do Vale do São Francisco esteve em Juazeiro [BA] durante o Congresso Brasileiro de Educação Ambiental Interdisciplinar (II COBEAI), ministrando a palestra "As Ciências Humanas e do Rio São Francisco". Naquela oportunidade, estudantes da Universidade Federal do Vale do São Francisco adquiriram obras distribuídas pelo Museu.

Com o mesmo objetivo, o Coordenador esteve em Pirapora [MG], em 31 de outubro de 2012, falando aos estudantes e professores do Instituto Federal do Norte de Minas sobre o tema "Rio São Francisco - História, navegação e cultura".

No período de 05 a 08 de maio de 2014, durante o IV Seminário Franco-Brasileiro Rios e Cidades na História do Brasil - Rio São Francisco [BA], o Coordenador do Museu e outros professores visitaram as cidades de Petrolina [PE], Paulo Afonso [BA], Juazeiro [BA], Remanso [BA] e Pilão Arcado [BA], ministrando palestras, visitando instituições de ensino e fotografando a região. Trabalhos apresentados no mencionado evento foram publicados em dois importantes periódicos de circulação internacional: a revista Confins e a Labor \& Engenho (ver Gandara, 2014; Théry, 2014 e 2015; Neves, 2015; Pachêco Filho, 2015; Rocha \& Oliveira, 2015; Miranda, 2015; Ribeiro, 2015; Porto \& Theis, 2015).

Anualmente, a equipe do Museu visita cidades da Bacia do São Francisco em trabalho de pesquisa e documentação fotográfica bem como para aquisição de objetos artesanais destinados ao acervo da instituição. pesquisa ao Rio Corrente,

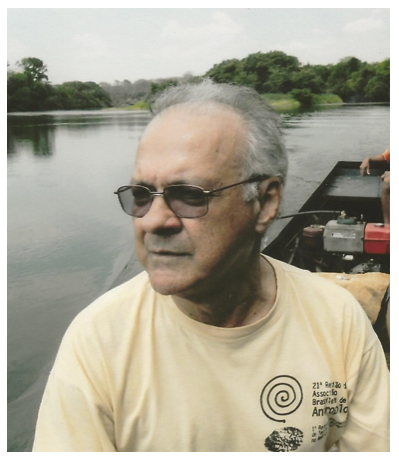
Juazeiro, Bom Jesus da Lapa, Santa Maria da Vitória [BA], Petrolina [PE], afluente do São Francisco Própria [SE], Pirapora, Guaicuí [MG], são cidades são-franciscanas onde (Foto: Tânia Cotta, 2013). a equipe já esteve.

O Coordenador do Museu Antropológico do Vale do São Francisco pertence aos quadros de uma instituição regional: a ACLECIA - Academia de Letras, Ciências e Artes do São Francisco, com sede em São Francisco [MG], cidade ribeirinha.

\subsection{Um Ponto de Encontro}

(C) Labor \& Engenho, Campinas [SP] Brasil, v.12, n.1, p.3-13, jan./mar. 2018. 
Orientado para o estudo e a pesquisa em Ciências Sociais, o Museu Antropológico do Vale do São Francisco tem um grande interesse em receber, em seu recinto, profissionais dessa área acadê-mica, para reuniões, seminários, simpósios etc. Recentemente, em 22 de junho de 2017, estiveram em visita ao Museu diversos historiadores do Instituto Histórico e Geográfico de Minas Gerais.

Sob a liderança do Dr. Marcelo Miranda Guimarães, a equipe do Museu da História da Inquisição esteve na sede do Museu Antropológico, em 2 de outubro de 2017, para conhecer o seu acervo e projeto expográfico.

\subsection{Palestras}

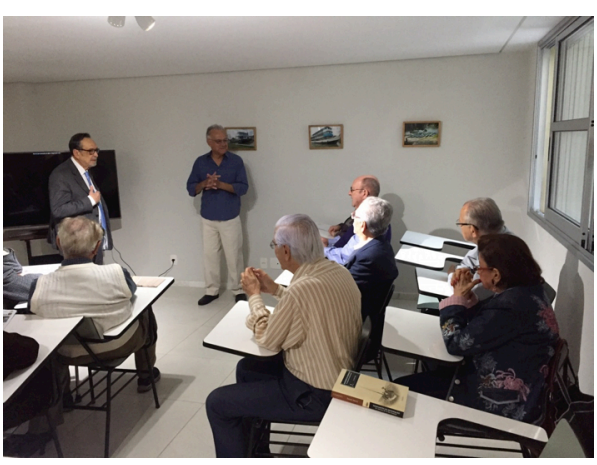

Figura 4. Historiadores do IHG-MG na sala de aulas do Museu Antropológico do Vale do São Francisco.

(Foto: Carlos Isoldi, 2017).

À disposição de estudantes, professores e do público em geral, o Museu Antropológico mantém um repertório de palestras sobre o Vale do São Francisco:

- As Ciências Humanas e o Rio São Francisco;

- Embarcações do Vale do São Francisco;

- Lúcio Cardoso e o regionalismo - Literatura e história;

- Museu Antropológico do Vale do São Francisco;

- O Médio São Francisco e os navegantes da integração - remeiros;

- O Médio São Francisco e os navegantes da integração - vapozeiros;

- Rio São Francisco - História, navegação e cultura (Exposição sobre o conteúdo do livro que tem este título);

- Vale do São Francisco - Um panorama de sua literatura;

- Vapor "Benjamim Guimarães" - Patrimônio dos ribeirinhos do São Francisco.

0 perfil de um historiador de prestígio, nascido na ribeira, foi publicado na Revista da Academia Mineira de Letras, e resumido numa palestra a cargo da equipe do Museu Antropológico:

- Francisco Iglesias - Intelectual múltiplo.

Outras palestras dizem respeito a temas sobre as origens da Antropologia, suas relações com outras disciplinas e a teoria antropológica:

- Antropologia e colonialismo;

- Contribuição interdisciplinar em Ciências Humanas;

- Olhares antropológicos.

O tema da história, das culturas indígenas e do indigenismo também foi contemplado. Veja o tema abaixo:

- O espetáculo das etnias indígenas no Brasil.

Outro tema de interesse geral consta no repertório de palestras do Museu:

- Cultura popular tradicional, ciência e sustentabilidade.

\subsection{Publicações}

A bibliografia produzida pela Coordenação do Museu Antropológico do Vale do São Francisco 
integra-se ao seu patrimônio, inclusive os direitos autorais das obras publicadas, os quais foram (são) revertidos para a manutenção e desenvolvimento da instituição. Vejamos a relação dos livros:

- Navegantes da Integração. 2a edição, Belo Horizonte: Editora UFMG, 2011, Coleção Humanitas.

- Rio São Francisco - História, navegação e cultura. Juiz de Fora: Ed. UFJF, 2009.

- Os remeiros do Rio São Francisco. São Paulo: Ed. Saraiva, 2004, Coleção Que história é esta?.

- Na carreira do Rio São Francisco. Belo Horizonte: Ed. Itatiaia, 2006, Coleção Reconquista do Brasil, no 237.

- Pirapora em tempos idos - Poesia, artigos e ensaios. 2aㅡ. ed., Belo Horizonte: Núcleo de Estudos do Vale do São Francisco, 2012.

- Médio São Francisco - Os homens do rio, sua linguagem, seu saber. Belo Horizonte: Núcleo de Estudos do Vale do São Francisco, 2013, Caderno no 2.

- Rio São Francisco - Fatos de sua história, traços de sua cultura. Ipatinga: Ed. Saramandaia; São Francisco: Aclecia - Academia de Letras, Ciências e Artes do São Francisco, 2016.

- Escritos antropológicos \& históricos. Belo Horizonte: Museu Antropológico do Vale do São Francisco / Instituto Histórico e Geográfico de Minas Gerais, 2018.

Esses títulos estão à venda na livraria do Museu ou podem ser adquiridos através da Internet.

\subsection{Amigos do Museu}

Em 22 de novembro de 2017, dois visitantes oriundos de cidades do Vale do São Francisco Dorinha Vargas e Marco Loro - propuseram a criação da sociedade AMIGOS DO MUSEU ANTROPOLÓGICO DO VALE DO SÃO FRANCISCO. Aprovada pela Diretoria, essa entidade orienta-se por objetivos educativos, contando com aproximadamente 420 seguidores. Seus temas preferenciais: preservação e revitalização dos ecossistemas são-franciscanos, defesa da biodiversidade, incentivo ao estudo e à pesquisa da cultura dos povos ribeirinhos.

\subsection{Missão e Objetivos}

A missão mais relevante do Museu Antropológico do Vale do São Francisco (MAVSF) será sempre a de projetar a cultura dos povos são-franciscanos no Brasil através das atividades de ensino e pesquisa sem evidentemente perder de vista as exposições permanentes e temporárias que constituem o fulcro de seus objetivos.

As visitas orientadas pela equipe do Museu são inteiramente gratuitas, e possibilitam uma "viagem" às culturas do Vale do São Francisco - às sub-regiões e aos afluentes. Ademais, grupos de estudantes poderão ouvir palestras sobre a região do São Francisco, ministradas pela Coordenação do Museu, utilizando as modernas tecnologias de educação.

O Museu também oferecerá minicursos e palestras à categoria dos professores do ensino médio. Poderão ser beneficiados os docentes das áreas de História, Sociologia, Geografia e disciplinas afins, bem como os estudantes universitários dessas áreas acadêmicas que manifestarem interesse em participar. Serão contratados professores/pesquisadores, com mestrado e doutorado, para ministrar esses cursos. Terão preferência os estudiosos e pesquisadores com trabalhos realizados na região.

Um programa complementar para visitantes de cidades ribeirinhas será a visita ao Aquário do São Francisco, mantido pela Fundação Zoobotânica de Belo Horizonte. 
Profissionais das artes plásticas que se dedicam à pintura, à escultura e à fotografia de caráter regionalista serão convidados para exposições temporárias na sede do Museu. Também serão acolhidos os documentaristas que realizarem trabalhos sobre o Vale do São Francisco - sobre sua história, seus povos e suas culturas.

Por fim, vale ressaltar que o MAVSF assume um compromisso, em seus estatutos, de colaborar com a pesquisa sobre a biodiversidade e os ecossistemas são-franciscanos, contribuindo assim para a sua preservação e revitalização.

\subsection{Público-alvo e Endereços}

Estudantes e professores da rede pública e particular de ensino constituem o público-alvo do Museu Antropológico do Vale do São Francisco. Ribeirinhos do Vale do São Francisco, em visita à Capital mineira, são acolhidos com grande interesse no recinto do Museu.

O público em geral, da Grande Belo Horizonte, os turistas e visitantes de outros Estados, também serão bem-vindos.

De fácil acesso, o Museu localiza-se nas proximidades do chamado "corredor cultural de Belo Horizonte". Vejamos, a seguir, os seus endereços:

- Rua Desembargador Alfredo Albuquerque, 49 - Santo Antônio 30330.250 - Belo Horizonte (MG)

Telefone: (31) 32961197 (manhã)

- Site: www.nevsf.org

- E-mail: <atendimento@mavsf.org> / <zanonineves@ig.com.br>

\section{Referências}

Gandara, G. (2014). Pilão Arcado e Remanso: patrimônios que dormitam. Labor \& Engenho, 8(3), 5-18. doi: https://doi.org/10.20396/lobore.v8i3.203

MAVS (2017). Mostruários do Museu Antropológico do Vale do São Francisco. Belo Horizonte: MAVS.

Miranda, L. (2015). Cidades, águas e ilhas no estuário amazônico. Labor \& Engenho, 9(2), 81-92. doi: https://doi.org/10.20396/lobore.v9i2.8635579

Neves, Z. (2017). “Uma bela viagem ao Rio São Francisco”. In: Memória cult. Ouro Preto: Ano VII, no 21, abril de 2017.

Neves, Z. (2016). "Museu Antropológico do Vale do São Francisco". Revista do Instituto Histórico e Geográfico de Minas Gerais. Belo Horizonte: Vol. 41.

Neves, Z. (2015). Vapor "Benjamim Guimarães". Patrimônio dos ribeirinhos do São Francisco. Labor \& Engenho, 9(2), 39-54. doi: https://doi.org/10.20396/lobore.v9i2.8635738

Neves, Z. (2009). Rio São Francisco - História, navegação e cultura. Juiz de Fora: Editora UFJF.

Pachêco Filho, A. (2015). "Empurrador de canoa não ganhava nada não". Os vareiros do rio Grajaú e a circulação de mercadorias, pessoas e sonhos. Labor \& Engenho, 9(2), 55-69. doi: https://doi.org/10.20396/ lobore.v9i2.8635574

Porto, J., \& Theis, I. (2015). Circuitos da Economia na fronteira amapaense: um híbrido de subsistemas para a sua reorganização espacial. Labor \& Engenho, 9(2), 101-114. doi: https://doi.org/10.20396/lobore.v9i2.8635578

Ribeiro, M. (2015). Infâncias do Semiárido lançando olhares. Labor e Engenho, 9(2), 93-100. doi: https:// doi.org/10.20396/lobore.v9i2.8635581 
Rocha, L., \& Oliveira, M. (2015). Imperatriz [MA] e Porto Nacional [TO]: duas cidades, um rio e muitas histórias. Labor \& Engenho, 9(2), 70-80. doi: https://doi.org/10.20396/lobore.v9i2.8635573

Théry, H. (2015). Retour dans la vallée du Rio São Francisco. Labor \& Engenho, 9(2), 18-38. doi: https:// doi.org/10.20396/lobore.v9i2.8635568

Théry, H. (2014). Des frontières pionnières. Labor \& Engenho, 8(3), 19-27. doi: https://doi.org/10.20396/ lobore.v8i3.204 